\title{
Malignant Exocervical Neoplasm
}

National Cancer Institute

\section{Source}

National Cancer Institute. Malignant Exocervical Neoplasm. NCI Thesaurus. Code C3554.

A malignant neoplasm that affects the exocervix. 